\title{
Presenting Amazon's Mechanical Turk as more than just a data sample - A study of MTurker experiences
}

Research Article

\author{
Jestine Philip ${ }^{1 *}$, and Mark A Davis ${ }^{2}$ \\ 1 University of New Haven College of Business \\ 2 University of North Texas
}

\begin{abstract}
Amazon's Mechanical Turk (MTurk) is an online crowdsourcing platform that is part of the digital gig economy, where MTurkers perform fast and repetitive gigs or microwork like taking surveys and performing data transcriptions, and are compensated for each completed task. The purpose of this research is to understand the work- and life-related implications for MTurkers. Drawing from the Psychology of Working Theory (PWT), we examined the role that income and volition play in determining satisfaction and stress among MTurkers. Results revealed that high volition MTurkers had higher job satisfaction, higher life satisfaction, and lower stress than low volition MTurkers. These findings help extend PWT to this contemporary and evolving form of working in the digital gig economy. Management scholars view gig work as an emerging trend and an addition to the list of notable research and practice gaps in organisational behaviour.
\end{abstract}

Keywords: Mechanical Turk; work volition; job satisfaction; stress

(C) Sciendo

\section{INTRODUCTION}

Amazon's Mechanical Turk (MTurk) is an online crowdsourcing platform, where workers earn money by performing quick and repetitive tasks like taking surveys. Individuals who register on the MTurk website for data collection are called 'requesters'. Requesters offer a fixed piece rate (typically a few cents) for successful completion of human intelligence tasks (HITs); where, a HIT is considered microwork that can often be completed in a few minutes (Little et al., 2009; Reddy et al., 2010). MTurk workers (henceforth, MTurkers) and requesters do not directly interact with each other and payments are facilitated through the platform upon completion of HITs. MTurk is part of the growing digital gig economy, in which more than 150 million workers from the U.S. and Western Europe participate (Manyika et al., 2016).

Two categorizations of the gig economy exist - 'digital' gig economy (comprising of microwork like MTurk and online freelancing like web content development) and 'physical' gig economy (includes services by Uber, TaskRabbit, and Airbnb, in which workers perform non-digital tasks) (Heeks, 2017). According to this classification, crowd work is a collective form of microwork, making MTurk a crowdsourcing platform that offers microwork. The digital economy has also been referred to as 'elance' economy (derived from 'internet freelancing') in management scholarship (Aguinis and Lawal, 2013; Cheung et al., 2017), wherein workers are hired on-demand for a digital gig via an online platform and complete tasks as they become available. Demographic surveys of thousands of MTurkers indicate that more than half of them are 21-35 years old (Ipeirotis, 2010) with an average age of 35.5 years (Michel et al., 2018). Many MTurkers are stay-at-home parents, with about $60 \%$ married or living with a partner, $33 \%$ single, and 
over 50\% female (Shapiro et al., 2013; Michel et al., 2018). These data closely approximate the general population at large as well as conventional samples in social sciences in terms of gender and race (Burnham et al., 2018), with the majority (83.5\%) being Caucasian (Shapiro et al., 2013). While most MTurk workers are in the U.S. and India (Ipeirotis, 2010), MTurkers also reside in 190 countries (Stewart et al., 2015) with samples outside the U.S being racially and ethnically diverse. Due to these similarities as well as being an inexpensive data source, MTurk has emerged as a popular choice for study samples among scholars worldwide in field of social sciences, including organisational behaviour and human resources (OB/HR) and organisational psychology (Chandler et al., 2014).

The increased reliance on MTurk samples prompted scholars to study the drawbacks of utilising MTurk. For example, Thomas and Clifford (2017) cautioned researchers about external and internal validity problems in MTurk samples. Concerns relating to data quality have also been raised as MTurkers are known to share information with fellow workers about available HITs and requesters, thereby allowing survey respondents to have prior knowledge of a study (Chandler et al., 2014). Despite these criticisms, MTurk continues to remain a frequent source for proxy data samples in behavioural management studies. While there have been empirical studies utilising MTurkers and papers written in favor of and against using them, our understanding of MTurkers as workers is minimal. Recognising this limitation, the current research focuses on the experiences of MTurkers in the digital gig economy. Specifically, we apply a theory of career development, Psychology of Working Theory (PWT), to understand how the freedom, or lack thereof, of MTurkers in choosing to perform MTurk work affects their satisfaction and stress. To this end, we pose the following research question - How are the occupational and life experiences of MTurkers shaped by their work volition and income? We recognise the dearth of studies on MTurkers in OB/HR literature and the under-utilisation of theory to bridge this gap. This study also attempts to extend the works of Brawley and Pury (2016), regarding MTurker job satisfaction and turnover, and Keith et al. (2017), who differentiated these workers based on their primary and secondary income.

\section{THEORETICAL BACKGROUND}

Given the changing nature of the occupational landscape since the digital revolution (1980s-2000s), there has been a recognised need in psychology-based vocational theories to understand the role that social and contextual factors play in career selection and career fulfillment for an individual (Blustein, 2013). Research grounded in vocational theories has demonstrated that the work experiences of employees with limited privilege in job choice differ from those of employees with greater freedom (Blustein, 2006). Broadly, there are two primary functions of the PWT; first, to explain the important elements that are involved in securing decent work, and second, to describe how performing decent work contributes to the satisfaction, work fulfillment, and well-being of individuals. Economic constraints like low income and family wealth represent crucial predictors of securing decent work (Huston and Bentley, 2010). According to the PWT, individuals with greater economic constraints are less likely to secure decent work (Duffy et al., 2016). Work volition, a key concept in the PWT, is defined as an individual's perceived capacity to make work-related choices despite potential constraints like financial hardships and family restrictions (Duffy et al., 2012). In addition, work - as a domain of life - produces high levels of stress in individuals. Boswell et al. (2004) investigated the lack of job control on undesirable employee outcomes in high-pressure and stressful work situations. They found that an employee who experiences stress from heavy workload and perceives little control or authority over how to meet these demands is unlikely to experience positive work outcomes.

\section{Amazon's Mechanical Turk and work volition}

For purposes of this research, 'high work volition' is defined as an MTurker's ability to choose the kind of work they wish to do (conventional jobs, MTurk work or other types of gig work like driving for Uber), their ability to have high level of control over their work of choice, and their ability to change their current work of choice if they wished to do so. In the same vein, 'low work volition' is defined as an MTurker's inability to choose the kind of work they wish to do, their inability to have high level of control over their work, and their inability to change their current work even if they wished to do so. An example high work volition MTurker is a college student who is mostly free from family/ financial constraints and, thus, able to voluntarily perform MTurk work. A second example is an entrepreneur (single or married, but without children) who runs their own business to secure primary income and performs MTurk work 
during their spare time. A physically disabled individual who works on the MTurk platform from home because their disability precludes performing conventional full-time jobs outside the home serves as an example of a low work volition MTurker. An individual experiencing a break in their career because of layoffs and poor job prospects due to a poor economy is also an example of a low volition MTurker, because this individual performs MTurk work parttime alongside performing other gigs in order to maintain an income while actively looking for traditional, full-time work. The demarcation of MTurkers into high and low volition workers based on their personal and professional constraints is consistent with prior research findings, which found that about $30 \%$ of independent workers earn their main income from doing gig work due to lack of better employment opportunities (Manyika et al., 2016).

\section{Amazon's Mechanical Turk and income categories}

Manyika et al. (2016) surveyed 8,000 workers across the U.S. and Europe and found that 20 to $30 \%$ of the working age population in these economies engaged in some form of independent work, wherein workers either derived their income solely from gig work (digital or physical) or performed gig work for additional income alongside being employed at a steady-paying job. Further, Kuhn and Galloway (2019) studied the income sources of MTurkers and categorised them as either working full-time on this online platform or using MTurk to supplement their income from a regular job. Consistent with these prior studies, the current research also categorises MTurkers as belonging to two income categories - primary income and secondary income. Specifically, a 'primary income MTurker' spends the most amount of time in a day on the MTurk website completing HITs, thereby earning a larger portion of their income from doing MTurk work, whereas a 'secondary income MTurker' spends limited amount of time in a day completing MTurk HITs while spending a majority of their time on other jobs, thereby earning a smaller portion of their income from doing MTurk work.

\section{HYPOTHESIS DEVELOPMENT}

\section{Direct effects of work volition on Amazon MTurker job satisfaction, life satisfaction, and stress}

Working individuals who possess high work volition tend to experience higher fulfillment, autonomy, and freedom to do the job (Allan et al., 2014; Spector, 1982). High volition also allows more freedom to make occupational choices despite constraints (Duffy et al., 2012). There is a strong correlation between work volition and job satisfaction (Duffy et al., 2013). Jabagi et al. (2019) offered that gig workers whose needs for volition and autonomy are met would experience high intrinsic motivation. By extension, we argue that MTurkers with high volition would experience satisfaction in their MTurk work.

With regards to life satisfaction, past research has consistently shown that work and non-work domains of an individual's life tend to spill over into another (Lambert, 1990; Adams et al., 1996). According to the PWT, work volition can affect both work and life-related outcomes and create a sense of control over job situations (Duffy et al., 2012) to increase life satisfaction in working adults (Duffy et al., 2013). Hence, high volition MTurkers would be expected to experience high life satisfaction.

Work stress arises from issues relating to job or role demands and job situations (Spielberger et al., 2003). One of the biggest reasons for heightened stress-levels in the (digital and physical) gig economy is the insecurities involved in performing these gigs. Fifty-two percent of workers surveyed agree that the gig economy lacks security while $27 \%$ claim that it can be exploitative (Business Reporter, 2017). Such uncertainties in a person's day-to-day work can lead to stress (Jacobs and Blustein, 2008). Research shows that working in an ambiguous employment market might feel significantly more stressful than being securely employed (Mantler et al., 2005). Furthermore, the constraints that low volition MTurkers have around personal finance and family also add to psychological stress, due to their low situational control (Spector, 1982; Lefcourt, 2013). Therefore,

Hypothesis 1: High work volition MTurkers will experience a) higher job satisfaction,

b) higher life satisfaction, and c) lower stress than low work volition MTurkers.

\section{Direct effect of income category on Amazon MTurker stress}

Since research on MTurkers has largely ignored their income and associated stress, we derive the current understanding of MTurker stress from study findings based on comparable samples of physical gig workers. Deliveroo, a UK-based food delivery service provider, employs gig workers to make deliveries on bicycles. These 
individuals, who can often be found cycling through London city traffic even on rainy days, are paid a fixed hourly rate with the remaining part of their income dependent on the number of deliveries they complete (The Guardian, 2017). The uncertainties in this particular type of gig employment include uncertain working hours, and in effect, uncertain amounts of money earned at the end of each working day. Even the distance to be cycled to make deliveries is oftentimes unknown to workers as they are restricted from viewing the delivery address until they have accepted the notification in the app to make that delivery. Making food deliveries for Uber (Uber Eats) also involves similar pay-related insecurities. Consequently, an individual who derives their primary income in such a volatile work environment, where daily wages are unpredictable and physical exertion is high, is likely to be distressed and burned out as compared to an individual working in an office space earning a steady monthly income.

With regards to MTurkers, primary income MTurkers spend much of their working hours on the MTurk platform, where HITs like surveys are highly repetitive and compensation is earned as micropayments (often in cents per HIT) (Reddy et al., 2010). Gig work is known to have higher job demands and dropout rates than traditional employment (SherpaShare, 2015), which relate to increased stress (Mantler et al., 2005). Keith et al. (2017) reported that primary income MTurkers were more likely to be unemployed from traditional jobs and have less income than MTurkers who are less reliant on this platform for work. Therefore, while both primary and secondary income MTurkers experience stress, the former should experience higher levels because of the increased time spent in this environment and the lack of regular employment. Therefore,

Hypothesis 2: Primary income MTurkers will experience higher stress than secondary income MTurkers.

\section{Moderating effects of income category on Amazon MTurker satisfaction}

Alongside the direct effects of work volition and income category on satisfaction and stress, we contend that primary and secondary income reflect distinct conditions that can alter the relationship between work volition and these outcomes. In particular, we view income category as a moderator variable capable of weakening the relationship between volition and satisfaction. The PWT posits that work volition is influenced by constraints like limited income (Super, 1953; Duffy et al., 2012). Income acts a barrier to work volition because the lack of income and a poor economy may restrict people from being able to choose the job they really desire (London, 2014). For example, in the case of a married individual with children who supports their family on a single income, a job loss and subsequent loss of income would drastically limit their standard of living, forcing a potentially hasty search for a replacement employment opportunity, which may not necessarily be the job of their choice (Leana and Feldman, 1995).

It is known that MTurkers report lower income compared to the general working population and primary income MTurkers earn less income than secondary income MTurkers (Keith et al., 2017). Research suggests that when an individual's income is exceptionally low such that it is a means for survival, work orientation becomes more extrinsic than intrinsic (Blustein, 2006). Although work can be a source of meaning and intrinsic fulfillment for some individuals, for many people working meets their survival needs (Blustein et al., 2008; Maslow, 1968). Therefore, among individuals with high volition, work can be intrinsically satisfying whereas for those with low volition, working is more likely a means for surviving. Additionally, whether a person has an intrinsic or extrinsic orientation towards work is affected by the remuneration they receive for doing it (Caldwell et al., 1983). Malka and Chatman (2003) found that for individuals with high intrinsic orientation and thereby, increased work volition, a higher income improved their job satisfaction. This suggests that the relationship between work volition and satisfaction could be affected by varying levels of income. While a higher income level offers a favorable context that enhances the volition-satisfaction relation, this relationship is weakened at extremely low-income levels. Given that primary income MTurkers earn less than secondary income MTurkers, we posit,

Hypothesis 3: Income category moderates the relationship between a) work volition and job satisfaction and b) work volition and life satisfaction, such that the relationship is weaker for primary income MTurkers than for secondary income MTurkers. 


\section{METHOD}

\section{Participants and procedure}

We collected the data from a sample of voluntary Amazon MTurkers. First, we created a requester account on Amazon's MTurk platform (www.mturk.com) with an email address and by following the prompts on the website to complete the account registration (Amazon Web Services, Inc., 2020). Then, we published the link for the online survey (which was set up using Qualtrics) on the platform. Only those MTurkers who met the following three pre-screening parameters were given access to the link - i) be at least 18 years of age, ii) must reside in the U.S. (only workers from the U.S. were considered for this study), and iii) have at least $95 \%$ approval rating on the MTurk website. Qualifying MTurkers were able to view the survey link and could choose whether or not they wished to complete the survey. The compensation offered for completing this survey was set at US $\$ 0.85$, which is consistent with the payment standard for MTurk survey takers (Buhrmester et al., 2011). A total of 396 responses from individual MTurkers were collected at two points in time. Of the 396, 220 responses were collected from MTurkers working evenings $(6 \mathrm{pm}$ to $10 \mathrm{pm})$ and 176 responses were collected from MTurkers working daytime (9 am to $2 \mathrm{pm}$ ). These time limits were applied in the MTurk platform to ensure that data from both full-time MTurkers (i.e., primary income) and part-time MTurkers (i.e., secondary income) were collected. Twenty responses were eliminated due to noncompletion, producing a final sample size of 373 MTurkers. The sample was $59.3 \%$ males and $40.7 \%$ females, with ages ranging from 21 to 69 years and an average of 46.2 years. About $2 \%$ of the MTurkers were over retirement age (66 years). Participants' ethnicities were 74\% Caucasian, 11\% African American, 6\% Asian, 4\% Hispanic/Latino, and 5\% other. Education-level of the sample was as follows: High School (23.1\%), Associate's Degree (14.3\%), Bachelor's Degree (45\%), Master's Degree (15.2\%), and Doctorate Degree (2.1\%). Approximately, $62 \%$ worked full-time and $15.4 \%$ worked part-time outside of MTurk, while the remaining $22.3 \%$ only performed MTurk-related work. For a majority of MTurkers, annual personal salary (75.5\%) and annual household salary $(60.3 \%)$ was less than US $\$ 60,000$. Based on type of HITs, $91 \%$ were survey takers, $6 \%$ did data entry, and $2 \%$ performed transcriptions.

\section{Measures}

Income category. Income category was captured by asking whether MTurk work was the individual's primary or secondary source of income. Primary income was defined as the income that they earn from the job that they spent the most amount of time doing in a day. Each participant's overall annual income (i.e., their total annual remuneration for all jobs including MTurk) was also captured.

Work volition. Work volition was measured using the scale developed by Duffy et al. (2012), which consists of 13 items. Items are based on a 7-point Likert scale ( $1=$ strongly disagree, $7=$ strongly agree). Some sample items are, "I feel total control over my job choices" and "I feel outside forces have really limited my work and career options". In their validation of the work volition scale, Duffy et al. (2012) reported an internal consistency of 0.86 . For the current MTurk sample, Cronbach's alpha was 0.87 . Respondent scores ranging from 4 through 7 were categorised as 'high work volition' and scores ranging from 1 through 3 were categorised as 'low work volition'.

Job satisfaction. Satisfaction with MTurk work was measured using the 3-item scale developed by Cammann et al. (1979). Each item uses a 5-point Likert scale ( $1=$ strongly disagree, $5=$ strongly agree). The term 'MTurk' was inserted into each scale item. Items are, "All in all, I am satisfied with my MTurk job", "In general, I don't like my MTurk job", and "In general, I like the MTurk work I do". For the MTurk sample, items had a Cronbach's alpha of 0.71 .

Life satisfaction. Life satisfaction was measured using the 5 -item scale developed by Diener et al. (1985). Items are based on a 5 -point Likert scale ( $1=$ strongly disagree, $5=$ strongly agree). A sample item is, "The conditions of my life are excellent". Based on responses from the present sample, Cronbach's alpha for the scale was 0.92 .

Stress. Perceived stress was measured using the 10-item scale developed by Cohen et al. (1994). Participants were asked to rate their feelings and thoughts during the last month. Items are based on a 5-point Likert scale (1 $=$ never, 5 = very often). A sample item is, "In the last month, how often have you felt that things were going your way?" Cronbach's alpha for this scale was 0.86 . 


\section{Data analysis}

Table 1 provides the descriptive statistics and correlations between the study variables.

Table 1: Overall descriptive statistics and correlations

\begin{tabular}{|c|c|c|c|c|c|c|c|c|}
\hline & Mean & S.D. & 1 & 2 & 3 & 4 & 5 & 6 \\
\hline 1. Work Volition & 3.97 & 1.07 & - & & & & & \\
\hline 2. Job Satisfaction & 3.7 & 0.87 & $0.32^{\star \star}$ & - & & & & \\
\hline 3. Life Satisfaction & 3.27 & 1.11 & $0.32^{\star *}$ & $0.29 * *$ & - & & & \\
\hline 4. Stress & 2.71 & 0.77 & $-0.41^{* *}$ & $-0.25^{\star}$ & $-0.38^{* *}$ & - & & \\
\hline 5. Age (years) & 46.16 & 142.61 & -0.01 & -0.03 & 0.07 & -0.01 & - & \\
\hline 6. Race ${ }^{a}$ & 1.40 & 0.85 & -1.07 & 0.04 & -0.08 & $0.16^{\star *}$ & -0.01 & - \\
\hline 7. Overall Salary & 45551.79 & 72208.4 & 0.06 & -0.02 & $0.18^{\star \star}$ & 0.01 & 0.01 & -0.02 \\
\hline
\end{tabular}

$N=373,{ }^{*} p<0.01$, two tailed. ${ }^{*} p<0.05$, two tailed.

a Majority respondents were Caucasian (Item 1 on Race scale)

Data were analysed using univariate analysis of variance and by performing mean contrasts. A univariate analysis of variance (ANOVA) was conducted to test the main effects in Hypotheses 1a, 1b, 1c, and 2. The moderation hypotheses, namely Hypotheses $3 \mathrm{a}$ and $3 \mathrm{~b}$, were tested using ANOVA by creating an interaction term for each model. The independent and moderator variables were mean centered to reduce multicollinearity (Aiken et al., 1991). Additionally, variance-inflation factor (VIF) for each interaction combination were calculated as 1.00 which was well below the cut-off of 10 indicating that multicollinearity would not hinder the interpretation of the results (Neter et al., 1996).

\section{RESULTS}

Hypothesis 1a posits that high work volition MTurkers have higher job satisfaction than low work volition MTurkers. Table 2 displays the univariate ANOVA results for job satisfaction. Results from the univariate analysis revealed a significant main effect of work volition on job satisfaction $F(1,369)=12.52, p<.001$. Mean job satisfaction for high volition $(\bar{x}=3.88)$ was higher than mean job satisfaction for low volition $(\bar{x}=3.54), \mathrm{F}(1,369)=12.52, \mathrm{p}<.001$, $95 \% \mathrm{Cls}[3.73,4.03][3.42,3.65]$. Hence, Hypothesis 1a is supported in that the relationship between work volition and job satisfaction is significant and high work volition MTurkers have higher job satisfaction than low work volition MTurkers.

Hypothesis $1 \mathrm{~b}$ predicts that high work volition MTurkers will have higher life satisfaction than low work volition MTurkers. Table 3 displays the univariate ANOVA results for life satisfaction. Analysis revealed that the main effect of work volition on life satisfaction was significant, $F(1,369)=5.02, p<.05$. Mean life satisfaction for the high volition group ( $\bar{x}=3.37$ ) was higher than the mean for the low volition group $(\bar{x}=3.08), F(1,369)=5.02, p<.05,95 \% \mathrm{Cls}$ $[3.17,3.56][2.93,3.23]$. Hence, Hypothesis $1 \mathrm{~b}$ is supported in that the relationship between work volition and life satisfaction is significant and high work volition MTurkers have higher life satisfaction than low work volition MTurkers.

Hypothesis 1c posits that low work volition MTurkers experience higher stress than high work volition MTurkers. Table 4 displays the univariate analysis for stress, which showed a significant main effect of work volition on stress, $F(1,368)=27.50, p<.001$. The mean for the low volition group $(\bar{x}=2.93)$ was higher than the mean for the high volition group $(\bar{x}=2.51), F(1,368)=27.50, p<.001,95 \%$ Cls $[2.83,3.02][2.38,2.64]$, providing support for Hypothesis 1c. 
Table 2: ANOVA results for job satisfaction

\begin{tabular}{cccccc}
\hline Predictor & $\begin{array}{c}\text { Sum of } \\
\text { Squares }\end{array}$ & df & $\begin{array}{c}\text { Mean } \\
\text { Square }\end{array}$ & F & p \\
\hline \hline (Intercept) & 4119.42 & 1 & 4119.42 & 5835.57 & 0.000 \\
Income Category & 5.25 & 1 & 5.25 & 7.43 & 0.007 \\
Work Volition & 8.84 & 1 & 8.84 & 12.52 & 0.000 \\
Income Category x Work Volition & 0.04 & 1 & 0.04 & 0.06 & 0.815 \\
Error & 260.48 & 369 & 0.71 & & \\
\hline
\end{tabular}

Table 3: ANOVA results for life satisfaction

\begin{tabular}{cccccc}
\hline Predictor & $\begin{array}{c}\text { Sum of } \\
\text { Squares }\end{array}$ & df & $\begin{array}{c}\text { Mean } \\
\text { Square }\end{array}$ & $\boldsymbol{F}$ & $\boldsymbol{p}$ \\
\hline \hline (Intercept) & 3113.44 & 1 & 3113.44 & 2612.76 & 0.000 \\
Income Category & 0.02 & 1 & 0.02 & 0.02 & 0.889 \\
Work Volition & 5.98 & 1 & 5.98 & 5.02 & 0.026 \\
Income Category x Work Volition & 13.51 & 1 & 13.51 & 11.34 & 0.001 \\
Error & 439.71 & 369 & 1.19 & & \\
\hline
\end{tabular}

Table 4: ANOVA results for stress

\begin{tabular}{cccccc}
\hline Predictor & $\begin{array}{c}\text { Sum of } \\
\text { Squares }\end{array}$ & df & $\begin{array}{c}\text { Mean } \\
\text { Square }\end{array}$ & F & p \\
\hline \hline (Intercept) & 1473.80 & 1 & 1473.80 & 3014.88 & 0.000 \\
Income Category & 1.95 & 1 & 1.95 & 3.99 & 0.047 \\
Work Volition & 13.44 & 1 & 13.44 & 27.50 & 0.000 \\
Error & 179.89 & 368 & 0.49 & & \\
\hline
\end{tabular}

Hypothesis 2 asserts that primary income MTurkers experience higher stress than secondary income MTurkers. The analysis of variance revealed a significant main effect of income category on stress, $F(1,368)=3.99, p<.05$ (Table 4). The mean for the primary income group $(\bar{x}=2.87)$ was higher than the mean for secondary income group $(\bar{x}=2.57), F(1,368)=3.99, p<.05,95 \%$ Cls $[2.74,3.00][2.47,2.67]$, providing support for Hypothesis 2 .

Hypothesis $3 a$ posits that income category moderates the relationship between work volition and job satisfaction, such that the relationship is weaker for primary income MTurkers than for secondary income MTurkers. ANOVA results revealed that the moderating effect of income category on work volition and job satisfaction was not significant (Table 2). Hence, Hypothesis $3 a$ is not supported. However, the main effect of income category on job satisfaction was significant $(p<0.01)$. Specifically, the mean job satisfaction for primary income MTurkers $(\bar{x}=3.58)$ was lower than that for secondary income MTurkers $(\bar{x}=3.84), F(1,369)=7.43, p<.01,95 \% \mathrm{Cls}[3.42,3.73]$ $[3.73,3.96]$. 


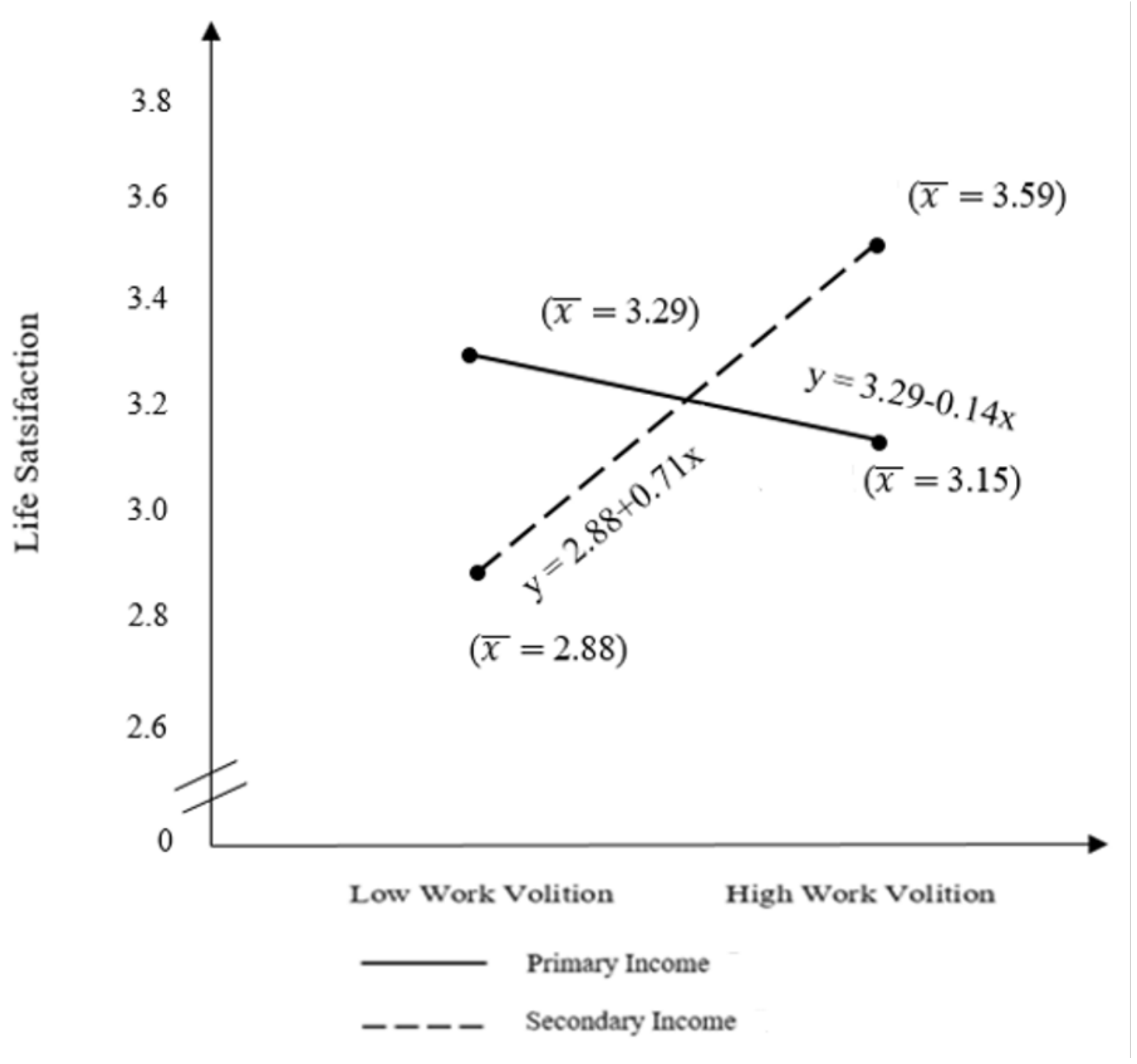

Figure 1: Interaction of work volition and income category on life satisfaction

Hypothesis $3 \mathrm{~b}$ posits that income category moderates the relationship between work volition and life satisfaction, such that the relationship is weaker for primary income MTurkers than for secondary income MTurkers. Results revealed that the moderating effect of income category on work volition and life satisfaction was significant $(p<$ 0.01) (Table 3). Figure 1 displays the slopes for each condition. Whereas the slope for the primary income was negative (-0.142) and non-significant, the slope for the secondary income line was positive (0.708) and significant $(p<.001)$. The higher absolute value of the secondary income slope indicates that the secondary income line is steeper and stronger in its relationship. In support of hypothesis $3 b$, these data evidence a stronger work volition-life satisfaction relationship among secondary income MTurkers than primary income MTurkers. Further, the mean life satisfaction for primary income MTurkers $(\bar{x}=3.21)$ was slightly lower than the mean life satisfaction for secondary income MTurkers $(\bar{x}=3.23), F(1,369)=11.34, p<.01,95 \%$ Cls $[3.01,3.41][3.09,3.38]$. 


\section{DISCUSSION}

Amazon Mechanical Turk has become a popular, contemporary work arrangement facilitated by digital technology. Because MTurkers are not restrained by conventional work boundaries like having to choose working hours and reporting to supervisors, individuals with varying demographic factors like different ages, education levels, and work experiences are self-selecting themselves for MTurk work. Many MTurkers are younger and more educated than the general population. Today, earning a college degree can mean high student loans and financial debts, however, being younger is also indicative of high work volition for college-attending students who have few family constraints. By this logic, MTurkers consist of a mix of high and low volition workers.

As more and more people join MTurk, the digital gig workforce cannot be ignored by management scholars and hence, there is an increasing need to study the attitudes and behaviours of these workers in this evolving work environment. This research specifically focused on MTurkers, recognising that this employment platform was not being sufficiently studied and that this would become problematic if continued to be ignored by OB/HR scholars. While researchers have acknowledged and studied the emergence of new workforces like millennials (e.g.: Gong et al., 2018) and new technologies like social media (e.g.: Duane and O'Reilly, 2017), we assert that a similar priority must be placed on studying the attitudinal experiences of MTurkers, as they form an integral part of the digital gig economy. Recently, scholars have begun to study different types of physical gig workers separately to capture their unique experiences - like Airbnb hosts (e.g., Lee and Kim, 2018), uber drivers (e.g., Ravenelle, 2019), and TaskRabbit workers (e.g., Hannák et al. (2017). However, for MTurk, research has mainly focused on worker demographics (Walters et al., 2018) and quality of collected data (Thomas and Clifford, 2017). To this end, we suggest that MTurkers must also be studied as a separate sample to capture their experiences.

As a guiding focus for this investigation, we posed the following research question: How are the occupational and life experiences of MTurkers shaped by their work volition and income? In general, we find that MTurkers hold more negative views of work and life when they have low volition and when their primary source of income is obtained from MTurk labour rather than traditional, stable employment. A detailed discussion of our results follows.

\section{Amazon MTurker satisfaction}

This study reveals that the effect of work volition was similar for both job satisfaction and life satisfaction. As hypothesised, high volition MTurkers had higher job satisfaction and life satisfaction. This finding is consistent with the PWT, which suggests that high work volition relates to higher levels of work fulfillment and overall well-being (Blustein, 2006; Duffy, Bott et al., 2013).

Next, with respect to the interaction between income category and work volition, life satisfaction, but not job satisfaction was subject to moderating effects. In particular, the relationship between work volition and life satisfaction was weaker (i.e., negative) for primary income MTurkers than for secondary income MTurkers. A possible explanation is that work volition is generally low among primary income MTurkers because this group might consist largely of individuals who are compelled to perform this work full-time due to their personal constraints. (For the present sample, $75 \%$ of primary income MTurkers had low work volition). We argue that because there is little difference in the low levels of volition for the majority of primary income MTurkers, the correlation between volition and life satisfaction for this group would be attenuated, thereby leading to the weaker relationship. An interesting finding regarding life satisfaction was that low volition MTurkers in the secondary income group had the lowest life satisfaction. Lachman and Weaver (1998) showed that a general sense of control is a predictor of life satisfaction among individuals at lower income levels (below US $\$ 50,000$ per year). The average overall annual salary of these MTurkers was US $\$ 40,020$, indicating that MTurkers not only experience a low sense of control in life but they are also navigating poor economic situations personally, all of which are contributing to a decrease in their life satisfaction.

For job satisfaction, although the interaction with income category did not yield statistical significance, primary income MTurkers did have lower job satisfaction than secondary income MTurkers. This dissatisfaction among primary income workers could be attributed to the amount of time that they spend in the uncertain work environment characterised by monotonous tasks and negligible pay. Prior studies of MTurkers have found that individuals who mainly did MTurk work for their income spent more than 40 hours a week on the platform (Ipeirotis, 2010). Another study of MTurker satisfaction revealed that MTurk requesters also play a crucial role in predicting worker satisfaction. Because requesters review MTurkers' completed tasks and make a determination on whether to approve or deny 
pay to a particular worker, poor requester behaviours like offering unfair pay for completed tasks have been shown to negatively impact job satisfaction (Brawley and Pury, 2016). This impact may be stronger for low volition, primary income MTurkers because they rely heavily on their approval ratings of completed HITs.

\section{Amazon MTurker stress}

As predicted, primary income MTurkers experienced more stress than secondary income MTurkers. These results suggest that individuals who spend most of their time in the MTurk environment to derive their primary income experience more stress than individuals with conventional jobs who do MTurk work on the side. Once again, the difference could be attributed to the nature of this work - highly repetitive and less predictability in terms of what HITs might be available each day resulting in erratic pay. Our sample had $91 \%$ survey takers; completing surveys is generally a monotonous task, wherein there is high likelihood of being bored. This leads to primary income MTurkers becoming more stressed and fatigued from laborious work. We also found that low volition MTurkers experienced higher stress than high volition MTurkers. This finding is supported by research on work stress, which suggests that people tend to be more stressed in situations where they feel they have less control (Houston, 1972). Low volition workers clearly have less control and freedom in their careers than do high volition workers.

\section{Implications for theory}

Findings from this study of MTurkers is further validation of the PWT, which substantiates the psychological role that work plays in an individual's life while acknowledging the relevant social and economic forces that facilitate and/or constrain aspects of working (Blustein, 2013). While previous empirical research has integrated the PWT in work volition, these studies viewed 'work' from a traditional perspective using conventional samples such as fulltime workers employed by firms (Zacher, 2014), health organisations (Duffy et al., 2013), and universities (Horton and Tucker, 2014). In contrast, this research examined decent work in a new and evolving work environment Mechanical Turk, a form of digital gig work, and used a sample of workers from this unconventional workspace. As described in our research, digital gig work like MTurk, is different from conventional full-time work and the experiences of workers in this new employment platform are unique. Moreover, the PWT proposes that decent work can lead to fulfillment and well-being. In this regard, findings from our study extends the application of the PWT by identifying the unique implications of MTurk work for individuals. This research also complements recent theoretical work like that of Jabagi et al. (2019), which demonstrated practical applications of motivational theories for gig workers.

\section{Implications for practice and policy}

Understanding the degree to which MTurkers experience satisfaction and stress can inform practice and policy by offering gig employers and policymakers an opportunity to recognise the idiosyncrasies of these workers and implement improvements to their existing working conditions. The (digital and physical) gig economy has implications for various HR functions like compensation, training, and performance management (Aguinis and Lawal, 2013). There has been an increasing push by gig workers to compel ridesharing companies like Uber and Lyft to recognise their drivers as employees (as opposed to independent contractors), so that these workers could be eligible for higher-than-minimum wages and employment benefits (DePillis, 2018; Tolentino, 2017). Similar efforts would extend to Amazon, which currently does not view MTurkers as employees. At present, the entire responsibility of learning to do MTurk work falls on the MTurker. An opportunity exists for Amazon to assess whether offering trainings and payfor-performance would help to improve MTurkers' work performance and potentially resolve requesters' concerns surrounding data quality and validity. For policy implications relating to external organizational factors, labour policymakers of countries where the gig economy is prevalent must hold companies and clients accountable for providing reasonable wages (HR.org, 2020) and analyze employment records and tax returns to identify evolving trends in work arrangements and human capital that contribute to their country's global competitiveness (Aguinis and Lawal, 2013).

\section{Limitations and future directions}

Importantly, the influence of the PWT variables on job satisfaction and life satisfaction were not uniform. For instance, the link between volition and life satisfaction was moderated by income category (primary versus secondary), but this was not the case for job satisfaction. This inconsistency warrants further investigation. It is possible that the low levels of income that MTurkers earn per HIT in this workspace prevent them from viewing these wages as 
important enough to positively impact their satisfaction with (digital or physical) gig work. We believe the concept of 'precarious work' could be useful for addressing this inconsistency. Blustein et al. (2016) discuss the tremendous rise and increasing prevalence of precarious work in the past few years due to rapid technological advances, globalisation, and a changing labour force. MTurk is an illustration of said precarious work and all features attributed to precarious work are prevalent in this environment. With scholars calling for more studies anchored in the PWT on modern day precarious work (Rubery et al., 2018), we recognise that future avenues for studying MTurker experience remain. Other factors like the changing demographics of MTurkers must also be given consideration in order to learn more about these evolving forms of working.

\section{CONCLUSION}

Mechanical Turk is an example of a popular means of working today. Management scholars note that emerging trends in the digital gig economy is an addition to the list of widely documented research and practice gaps in organisational behaviour and organisational psychology (Aguinis and Lawal, 2013; Cascio and Aguinis, 2008). Moving beyond analyzing MTurk from the standpoint of a data sample, this paper considered these workers' freedom to make work-related decisions as a factor for understanding their experiences in the gig economy. Studying the levels of satisfaction among MTurkers can inform management research and practice because of the unique circumstances of gig work and the absence of best practices for managing gig workers.

\section{References}

Adams, G. A., King, L. A., \& King, D. W. (1996). 'Relationships of job and family involvement, family social support, and work-family conflict with job and life satisfaction'. Journal of Applied Psychology, 81:4, 411.

Aguinis, H., \& Lawal, S. O. (2013). 'eLancing: A review and research agenda for bridging the sciencepractice gap'. Human Resource Management Review, 23:1, 6-17.

Allan, B. A., Autin, K. L., \& Duffy, R. D. (2014). 'Examining social class and work meaning within the psychology of working framework'. Journal of Career Assessment, 22:4, 543-561.

Amazon Web Services, Inc. (2020). Setting Up Accounts and Tools. Retrieved from https:// docs.aws.amazon.com/AWSMechTurk/latest/ AWSMechanicalTurkGettingStartedGuide/SetUp. html

Blustein, D. L. (2006). The psychology of working: A new perspective for career development, counseling, and public policy. Mahwah, NJ: Erlbaum.

Blustein, D. (2013). The psychology of working: A new perspective for career development, counseling, and public policy. Routledge.

Blustein, D. L., Kenna, A. C., Gill, N., \& DeVoy, J. E. (2008). The psychology of working: A new framework for counseling practice and public policy. The Career Development Quarterly, 56:4, 294-308.
Boswell, W. R., Olson-Buchanan, J. B., \& LePine, M. A. (2004). 'Relations between stress and work outcomes: The role of felt challenge, job control, and psychological strain'. Journal of Vocational Behavior, 64:1, 165-181.

Brawley, A. M., \& Pury, C. L. (2016). 'Work experiences on MTurk: Job satisfaction, turnover, and information sharing'. Computers in Human Behavior, 54, 531546.

Bucher, E., Fieseler, C., \& Lutz, C. (2019). 'Mattering in digital labor'. Journal of Managerial Psychology.

Buhrmester, M., Kwang, T., \& Gosling, S. D. (2011). 'Amazon's Mechanical Turk: A new source of inexpensive, yet high-quality, data?'. Perspectives on Psychological Science, 6:1, 3-5.

Burnham, M. J., Le, Y. K., \& Piedmont, R. L. (2018). 'Who is Mturk? Personal characteristics and sample consistency of these online workers'. Mental Health, Religion \& Culture, 21:9-10, 934-944.

Business Reporter. (2017). The top five advantages and disadvantages of gig economy workers. https:// business-reporter.co.uk/2017/12/28/top-fiveadvantages-disadvantages-gig-economy-workers/ [Accessed 31 March 2018]

Caldwell, D. F., O'Reilly, C. A., \& Morris, J. H. (1983). 'Responses to an organizational reward: A field test of the sufficiency of justification hypothesis'. Journal of Personality and Social Psychology, 44:3, 506. 
Cammann, C., \& Fichman, M. J. D., \& Klesh, J. (1979). The Michigan organizational assessment questionnaire.

Cascio, W. F., \& Aguinis, H. (2008). 'Research in industrial and organizational psychology from 1963 to 2007: changes, choices, and trends'. Journal of Applied Psychology, 93:5, 1062.

Cheung, J. H., Burns, D. K., Sinclair, R. R., \& Sliter, M. (2017). 'Amazon Mechanical Turk in organizational psychology: An evaluation and practical recommendations'. Journal of Business and Psychology, 32:4, 347-361.

Chandler, J., Mueller, P., \& Paolacci, G. (2014). 'Nonnaïveté among Amazon Mechanical Turk workers: Consequences and solutions for behavioral researchers'. Behavior Research Methods, 46:1, 112-130.

Cohen, S., Kamarck, T., \& Mermelstein, R. (1994). Perceived stress scale. Measuring stress: A guide for health and social scientists.

Conley, T. G. (1999). 'GMM estimation with cross sectional dependence'. Journal of Econometrics, $92: 1,1-45$.

DePillis, L. (2018). For gig eceonomy workers in these states, rights are at risk. CNNMoney. http://money. cnn.com/2018/03/14/news/economy/handygig-economy-workers/index.html [Accessed 30 January 2019].

Diemer, M. A., \& Rasheed Ali, S. (2009). 'Integrating social class into vocational psychology: Theory and practice implications'. Journal of Career Assessment, 17:3, 247-265.

Diener, E. D., Emmons, R. A., Larsen, R. J., \& Griffin, S. (1985). 'The satisfaction with life scale'. Journal of Personality Assessment, 49:1, 71-75.

Duane, A., \& O'Reilly, P. (2017). A conceptual stagesof-growth model for managing a social media business profile. The Irish Journal of Management, 36:2, 78-98.

Duffy, R. D., Blustein, D. L., Diemer, M. A., \& Autin, K. L. (2016). 'The psychology of working theory'. Journal of Counseling Psychology, 63:2, 127.

Duffy, R. D., Bott, E. M., Allan, B. A., \& Torrey, C. L. (2013). 'Examining a model of life satisfaction among unemployed adults'. Journal of Counseling Psychology, 60:1, 53.

Duffy, R. D., Diemer, M. A., \& Jadidian, A. (2012). 'The development and initial validation of the Work Volition Scale-Student Version'. The Counseling Psychologist, 40:2, 291-319.

Duffy, R. D., Diemer, M. A., Perry, J. C., Laurenzi, C., \& Torrey, C. L. (2012). 'The construction and initial validation of the Work Volition Scale'. Journal of
Vocational Behavior, 80:2, 400-411.

Gong, B., Ramkissoon, A., Greenwood, R. A., \& Hoyte, D. S. (2018). 'The Generation for Change: Millennials, Their Career Orientation, and Role Innovation'. Journal of Managerial Issues, 30:1, 82-6.

Hannák, A., Wagner, C., Garcia, D., Mislove, A., Strohmaier, M., \& Wilson, C. (2017). Bias in online freelance marketplaces: Evidence from taskrabbit and fiverr. In Proceedings of the 2017 ACM conference on computer supported cooperative work and social computing (pp. 1914-1933).

Heeks, R. (2017). Decent work and the digital gig economy: a developing country perspective on employment impacts and standards in online outsourcing, crowdwork, etc. Development Informatics Working Paper, (71).

Houston, B. K. (1972). 'Control over stress, locus of control, and response to stress'. Journal of Personality and Social Psychology, 21:2, 249.

Horton, J., \& Tucker, F. (2014). 'Disabilities in academic workplaces: Experiences of human and physical geographers'. Transactions of the Institute of British Geographers, 39:1, 76-89.

HR.org Legal Resources. (2020). Policies to Consider in the Gig Economy. Retrieved from https://www. hg.org/legal-articles/policies-to-consider-in-thegig-economy-51885

Huston, A. C., \& Bentley, A. C. (2010). 'Human development in societal context'. Annual Review of Psychology, 61, 411-437.

Huff, C., \& Tingley, D. (2015). "Who are these people?" Evaluating the demographic characteristics and political preferences of MTurk survey respondents'. Research \& Politics, 2:3, 2053168015604648.

Ipeirotis, P. (2010). Demographics of Mechanical Turk. Working Paper CeDER-10-01, New York University, Stern School of Business. Available at http://hdl.handle.net/2451/29585

Jacobs, S. J., \& Blustein, D. L. (2008). 'Mindfulness as a coping mechanism for employment uncertainty'. The Career Development Quarterly, 57:2, 174-180.

Jabagi, N., Croteau, A. M., Audebrand, L. K., \& Marsan, J. (2019). 'Gig-workers' motivation: thinking beyond carrots and sticks'. Journal of Managerial Psychology.

Keith, M.G., Tay, L. and Harms, P.D. (2017). 'Systems perspective of Amazon Mechanical Turk for organizational research: review and recommendations.' Frontiers in Psychology, 8:1, 1-19.

Kuhn, K. M., \& Galloway, T. L. (2019). 'Expanding perspectives on gig work and gig workers'. Journal 
of Managerial Psychology.

Lambert, S. J. (1990). 'Processes linking work and family: A critical review and research agenda'. Human Relations, 43:3, 239-257.

Leana, C. R., \& Feldman, D. C. (1995). 'Finding new jobs after a plant closing: Antecedents and outcomes of the occurrence and quality of reemployment'. Human Relations, 48:12, 1381-1401.

Lee, S., \& Kim, D. Y. (2018). 'The effect of hedonic and utilitarian values on satisfaction and loyalty of Airbnb users'. International Journal of Contemporary Hospitality Management.

Lefcourt, H. M. (Ed.). (2013). Research with the locus of control construct: extensions and limitations. Elsevier.

Liden, R. C., Wayne, S. J., Kraimer, M. L., \& Sparrowe, R. T. (2003). 'The dual commitments of contingent workers: An examination of contingents' commitment to the agency and the organization'. Journal of Organizational Behavior: The International Journal of Industrial, Occupational and Organizational Psychology and Behavior, $24: 5,609-625$

Little, G., Chilton, L. B., Goldman, M., \& Miller, R. C. (2009). 'Turkit: tools for iterative tasks on mechanical turk'. In Proceedings of the ACM SIGKDD workshop on human computation (pp. 2930).

London, M. (2014). 'Career barriers: How people experience, overcome, and avoid failure'. Psychology Press.

Mantler, J., Matejicek, A., Matheson, K., \& Anisman, H. (2005). 'Coping with employment uncertainty: a comparison of employed and unemployed workers'. Journal of Occupational Health Psychology, 10:3, 200.

Malka, A., \& Chatman, J. A. (2003). 'Intrinsic and extrinsic work orientations as moderators of the effect of annual income on subjective well-being: A longitudinal study'. Personality and Social Psychology Bulletin, 29:6, 737-746.

Maslow, A. (1968). 'Some educational implications of the humanistic psychologies'. Harvard Educational Review, 38:4, 685-696.

Manyika J, Lund S, Bughin J, Robinson K, Mischke J, Mahajan D. (2016). 'Independent work: Choice, necessity, and the gig economy'. McKinsey Global Institute.

Michel, J. S., O’Neill, S. K., Hartman, P., \& Lorys, A. (2018). 'Amazon's Mechanical Turk as a viable source for organizational and occupational health research'. Occupational Health Science, 2:1, 8398.
Neter, J., Kutner, M.H., Nachtsheim, C.J. and Wasserman, W. (1996). Applied linear statistical models, Irwin, Chicago, IL.

Ravenelle, A. J. (2019). "We're not uber:" control, autonomy, and entrepreneurship in the gig economy'. Journal of Managerial Psychology.

Reddy, S., Estrin, D., Hansen, M., \& Srivastava, M. (September, 2010). 'Examining micro-payments for participatory sensing data collections'. In Proceedings of the 12th ACM international conference on Ubiquitous computing (pp. 33-36).

Rubery, J., Grimshaw, D., Keizer, A., \& Johnson, M. (2018). 'Challenges and contradictions in the 'normalising' of precarious work'. Work, Employment and Society, 32(3), 509-527.

Shapiro, D. N., Chandler, J., \& Mueller, P. A. (2013). Using Mechanical Turk to study clinical populations. Clinical Psychological Science, 1:2, 213-220.

SherpaShare. (2015). The top demographic trends of the on-demand workforce. https://sherpashare. com/share/the-top-demographic-trends-of-the-ondemand-workforce/ [Accessed 31 March 2018].

Spector, P. E. (1982). 'Behavior in organizations as a function of employee's locus of control'. Psychological Bulletin, 91:3, 482.

Spielberger, C. D., Vagg, P. R., \& Wasala, C. F. (2003). Occupational stress: Job pressures and lack of support.

Stewart, N., Ungemach, C., Harris, A. J., Bartels, D. M. Newell, B. R., Paolacci, G., \& Chandler, J. (2015). The average laboratory samples a population of 7,300 Amazon Mechanical Turk workers. Judgment and Decision Making, 10:5, 479-491.

Super, D. E. (1953). 'A theory of vocational development'. American Psychologist, 8(5), 185.

The Guardian. (2017). Gig economy ruling has Deliveroo riders without rights and buying their own kit. https:// www.theguardian.com/business/2017/nov/19/gigeconomy-ruling-deliveroo-riders-equipment-basicemployment-rights [Accessed 31 March 2018].

Thomas, K. A., \& Clifford, S. (2017). Validity and Mechanical Turk: An assessment of exclusion methods and interactive experiments. Computers in Human Behavior, 77, 184-197.

Tolentino, J. (2017). The gig economy celebrates working yourself to death. The New Yorker. https:// www.newyorker.com/culture/jia-tolentino/the-gigeconomy-celebrates-working-yourself-to-death [Accessed 31 March 2018].

Tosti-Kharas, J., \& Conley, C. (2016). 'Coding psychological constructs in text using Mechanical Turk: A reliable, accurate, and efficient alternative'. Frontiers in Psychology, 7, 741 
Walters, K., Christakis, D. A., \& Wright, D. R. (2018). Are Mechanical Turk worker samples representative of health status and health behaviors in the US?. Plos One, 13(6).

Zacher, H. (2014). 'Individual difference predictors of change in career adaptability over time'. Journal of Vocational Behavior, 84:2, 188-198. 